\title{
SURFACE ANALYSIS OF $\gamma$-RAY IRRADIATION MODIFIED PBO FIBER
}

\author{
C.H. Zhang ${ }^{1}$, Y.D. Huang ${ }^{1}$, Y.D. Zhao ${ }^{2}$ \\ ${ }^{1}$ Department of applied chemistry, Faculty of science, Harbin institute of technology, Harbin 150001, \\ People's republic of China, \\ ${ }^{2}$ School of materials. Harbin institute of technology, Harbin 150001, People's republic of China
}

\section{Introduction}

Poly [p-phenylene benzobisoxazole] (PBO) can be manufactured into an organic fiber exhibiting high tensile strength and modulus with a low density, which results in exceptionally high specific mechanical properties [1,2]. Therefore, PBO fiber is a good candidate as the reinforcement for polymer composites. Mechanical properties of composites primarily depend on the fiber and the matrix properties, the fiber/matrix interface also plays a critical role in controlling the overall properties of the composites, such as off-axis strength, fracture toughness and environmental stabilities [3-5], However, the interfacial adhesion between PBO fiber and most polymer matrix is poor due to the surface of PBO fiber being chemical inert and smooth produced by its high crystallinity and the lack of polar functional groups in the polymer repeat unit $[6,7]$. Therefore, the surface modification of PBO fiber is of great importance in a field of composite application. Surface modification is accomplished through different type of treatment: plasma modification, corona and thermal treatment, and chemical coupling method. The ultimate goal of these treatments is to change the surface chemistry and microstructure of the material and thus modulate a number of properties such as roughness, surface free energy, reactivity, etc. [8-10].

Especially, the modification of PBO fiber surface has been the goal of many efforts in the field of composites, as the ultimate performance of these advanced materials is influenced by the quality of the fiber/matrix interface. In the case of PBO fiber, the $\gamma$-ray irradiation treatment method has been one of the methods newly studied as a surface modification that offers several advantages over other treatments. One primary advantage of the $\gamma$-ray irradiation treatment method is that the mechanical properties of the fiber are not significantly degraded if the conditions are controlled. Another important advantage is that the $\gamma$-rays can penetrate batches of materials $(1-5 t)$ [11]. Therefore, $\gamma$-ray irradiation technology can be used in industrial applications for fiber modification.

In this paper, the surface of PBO fiber has been modified by mutual irradiation of $\gamma$-ray with a solution of epichlorohydrin and acetone. The surface characteristics as well as the modification mechanism of $\gamma$-ray irradiation modified PBO fiber are investigated by $\mathrm{X}$-ray photoelectron spectroПОЛЗУНОВСКИЙ АЛЬМАНАХ №1-2 2007 scopy (XPS), surface free energy analysis, atomic force microscopy (AFM) and hydrogen nuclear magnetism resonance ( ${ }^{1} \mathrm{H}$ NMR). Surface free energy analysis and surface morphological observation are correlated with the results of XPS and ${ }^{1} \mathrm{H}$ NMR.

\section{Experimental}

\subsection{Materials}

The PBO fiber, namely HIT-2004 provides by Harbin Institute of Technology. Its average diameter is $15.0 \mu \mathrm{rn}$. The measured tensile strength and tensile module are about 3.6 and $260 \mathrm{GPa}$, respectively. The PBO model compound used for ${ }^{1} \mathrm{H}$ NMR analysis is synthesized in Harbin Institute of Technology as follows:

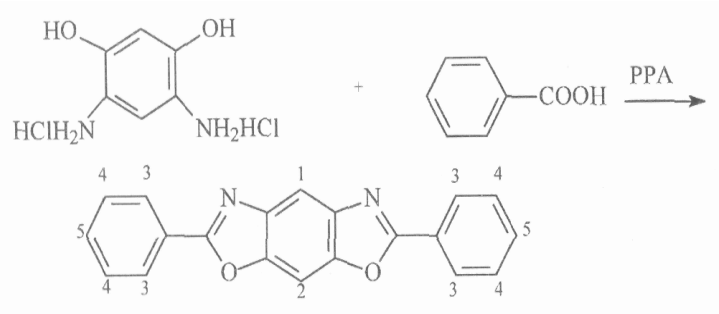

The epoxy resin serviced as the wetting agent is Epon828 from Shell Chemical Co. This epoxy resin is a kind of diglycidyl ether of bisphenol A type two-functional epoxy resin, it can be resolved in acetone in any ratio. The epichlorohydrin and acetone are supplied by Shanghai Chemical Corporation.

\section{2. $\gamma$-ray irradiation treatment}

PBO fiber and PBO model compound are washed repeatedly with acetone for $48 \mathrm{~h}$, and then dried at $80^{\circ} \mathrm{C}$ for $4 \mathrm{~h}$. Some of the fiber and the model compound serve as the surface modification, and some serve as compared analysis samples. The dried fiber and model compound are immersed in a solution of epichlorohydrin and acetone in a ratio of $1: 2$ by weight, and then irradiate using a ${ }^{60} \mathrm{Co}$ source with the energy of 1.17 $-1.33 \mathrm{MeV}$ and intensity of $1.5 \times 10^{4} \mathrm{Ci}$. In the irradiation treatment, the irradiation dose rate is 4.8 $\mathrm{kGy} \mathrm{h}^{-1}$, and the irradiation dose is $30 \mathrm{kGy}$. After irradiation treatment, the samples are taken out from the grafting solution and then are washed repeatedly again with acetone for $48 \mathrm{~h}$ and then dried at $80^{\circ} \mathrm{C}$ for $4 \mathrm{~h}$ for preparing analysis.

2.3. Surface free energy measurement of PBO fiber 
Kealble proposed that the dispersive component $\left(\gamma_{f}^{d}\right)$ and the polar component $\left(\gamma_{f}^{p}\right)$ of a fiber can be determined by two liquid dynamic contact angle analysis (DCAA). In this work, the PBO fiber surface free energy $\left(\gamma_{f}^{\top}\right)$ and their $\gamma_{f}^{d}$ and $\gamma_{f}^{p}$ are determined by DCAA, all the measurements are carried out with a dynamic capil lary method. In the experiment, some bundles of fiber are aligned and inserted into a polyethylene tube with diameter $2 \mathrm{~mm}$ and length $40 \mathrm{~mm}$. The bundles protrude $2 \mathrm{~mm}$ outside the tube. The ends of the bundles are impregnated in the liquids of second vaporized water and normal octane, respectively. At the same time, the contact angle, adsorption amount, the change of surface free energy of the fiber and the time of impregnation are calculated using Eqs. (I) - (3) $[12,13]$ and the results are automatically recorded.

$$
\begin{aligned}
& \gamma_{f v}-\gamma_{f 1}=\frac{64(1-\varepsilon)^{2} H^{2} \rho_{f} \eta m^{2}}{k^{2} \varepsilon^{3} v_{T} \omega_{f} d_{f} \rho_{1}^{2} t} \\
& \cos \theta=\frac{\gamma_{f v}-\gamma_{f 1}}{\gamma_{1}} \\
& \Delta m=m_{1}-m
\end{aligned}
$$

where $\gamma_{\mathrm{f} 1}$ is the surface free energy of the fiber-immersion liquid interface, and $\gamma_{\mathrm{fv}}$ is the surface free energy of the fiber in equilibrium with the saturated vapor; $\gamma_{1}$ is the surface tension of the immersion liquid; $\varepsilon$ is the void volume fraction in the tube ( $\varepsilon$ is bewteen 0.48 and 0.52 ); $H, \rho_{f}, d_{f}$ are the length, the density and diameter of the fiber, respectively; $\eta$ is the viscosity of the immersion liquid; $k$ is the hydraulic constant; $V_{T}$ is the total volume of the system; $m$ is the weight of the fiber bundle before immersion; $t$ is the time of the immersion equilibrium; $\theta$ is the dynamic contact angle between the fiber and the immersion liquid; $\Delta \mathrm{m}$ is the amount of immersion liquid adsorbed by the fiber at immersion equilibrium; $m_{1}$ is the weight of the fiber bundle at immersion equilibrium.

The dynamic contact angle is used to calculate the fiber surface free energy according to Kealble Eq. [14].

$$
\begin{aligned}
& \gamma_{1}^{T}(1+\cos \theta)=2\left(\gamma_{1}^{p} \gamma_{s}^{p}\right)^{1 / 2}+2\left(\gamma_{1}^{d} \gamma_{s}^{p}\right)^{1 / 2} \\
& \gamma_{f}^{T}=\gamma_{f}^{d}+\gamma_{f}^{p}
\end{aligned}
$$

where $y_{f}^{T}, y_{f}^{d}$, and $y_{f}^{p}$ are the total surface free energy, dispersive component energy and polar component energy of the fiber, respectively. $\gamma_{1}{ }^{\top}$, $\gamma_{1}{ }^{d}$, and $\gamma_{1}{ }^{p}$ are the surface tension of an immer-

\begin{tabular}{|c|c|c|c|c|}
\hline $\begin{array}{l}\text { Surface } \\
\text { energy } \\
\text { (dyn } \mathrm{cm}^{-} \\
\left.{ }^{1}\right)\end{array}$ & $\begin{array}{l}\text { Temper- } \\
\text { ature }\left({ }^{\circ} \mathrm{C}\right)\end{array}$ & $\gamma_{1}^{\top}$ & $\gamma_{1}{ }^{d}$ & $\gamma_{1}{ }^{p}$ \\
\hline $\begin{array}{l}\text { Second } \\
\text { vaporized } \\
\text { water } \\
\text { Normal } \\
\text { octane }\end{array}$ & $\begin{array}{l}20 \\
20\end{array}$ & $\begin{array}{l}72.8 \\
21.8\end{array}$ & $\begin{array}{l}21.8 \\
21.8\end{array}$ & $\begin{array}{l}51.0 \\
0\end{array}$ \\
\hline
\end{tabular}
sion liquid and its dispersive and polar component, respectively. The surface tensions of liquids are listed in Table 1 [15]. The value of test is more than 20 successful measurements.

Table 1 - The surface tensions of two liquids

\section{fiber}

\subsection{Surface chemical analysis of PBO}

Surface chemical analysis of the fiber before and after irradiation treatment are carried out by X-ray photoelectron spectroscopy (XPS) on a Shimadzu ESCA 750.

$\mathrm{X}$-ray photoelectron spectrometer using $\mathrm{Mg}$ $\mathrm{K} \alpha \mathrm{X}$-rays at power of $240 \mathrm{~W}$. The instrument is calibrated by Ag 3d spectra which has a peak half width and height of $1.15 \mathrm{eV}$ and $350 \mathrm{kcp}$, respectively. The voltage and current for the excited state of $\mathrm{Mg} \mathrm{K \alpha}$ are $8 \mathrm{kV}$ and $30 \mathrm{~mA}$.

Different functional groups are evaluated by curve fitting of $C_{1 s}$ spectrum using CaussianLorentzian distribution [16].

\subsection{Grafting reaction mechanism analys-} is

High-energy $\gamma$-ray irradiation has not only irritated the PBO fiber polymer to produce active free radicals but also irritated epichlorohydrin molecule to produce active radicals. Therefore, the chemical reactions between those active free radicals are produced, i.e. some polar groups produced by epichlorohydrin are grafted onto the PBO fiber surface. 'H NMR analysis can identify hydrogen containing fragments due to its ability to distinguish different characteristic hydrogen and to provide the chemical shift of hydrogen containing fragment by use scanning ${ }^{1} \mathrm{H}$ NMR spectrum. So it can be used to determine the change of polymer chemical structure. In this work, low molecule PBO model compound instead of PBO fiber, which does not resolve in any solvent, is tested by liquid ${ }^{1} \mathrm{H}$ NMR $(400 \mathrm{MHz}$, trifluoroacetic acid as solution). It can better understand the mechanism of the grafting reaction between PBO model compound and epichlorohydrin from the ${ }^{1} \mathrm{H}$ NMR spectrum. 


\section{AFM}

\subsection{Fiber surface topography analysis by}

Atomic force microscopy (AFM) measurements are performed with a Nanoscope III instrument manufactured by Digital Instruments Co. A single PBO fiber is fastened to a steel sample mount using the tapping mode. Roughness analysis is carried out from the images obtained over a $2 \mu \mathrm{m} \times 2 \mu \mathrm{m}$ area.

\section{Results and discussion}

XPS wide-scan $C_{1 s}$ spectra of untreated and 30 kGy irradiated PBO fibers are shown in Fig. 1. As shown in Fig.1b, there are distinct group peaks of $\mathrm{C}-\mathrm{C}, \mathrm{C}-\mathrm{O}, \mathrm{C}=\mathrm{N}, \quad \mathrm{C}-\mathrm{C} 1, \mathrm{COOH}$ and $\mathrm{C}-\mathrm{NH}_{2}$, which represents the major constitute of the irradiated PBO fiber surfaces. $\mathrm{No} \mathrm{COOH}$ and $\mathrm{C}-\mathrm{NH}_{2}$ groups peak is detected from the spectra (Fig. la) on the surface of untreated PBO fiber. Also, as expect, the oxygen-including peak area (peak $1+$ peak 2 ) of irradiated PBO fiber is increased according to the oxygen content.

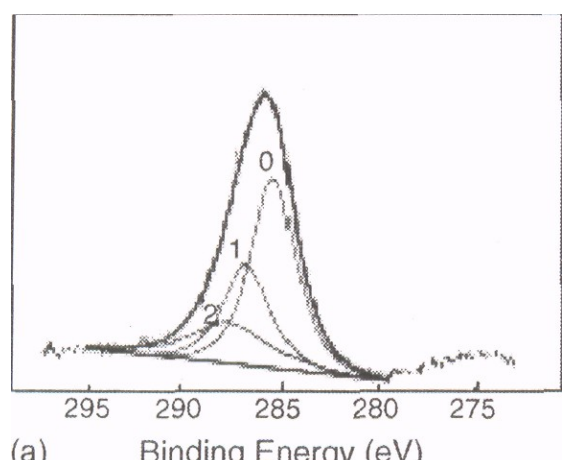

(a)

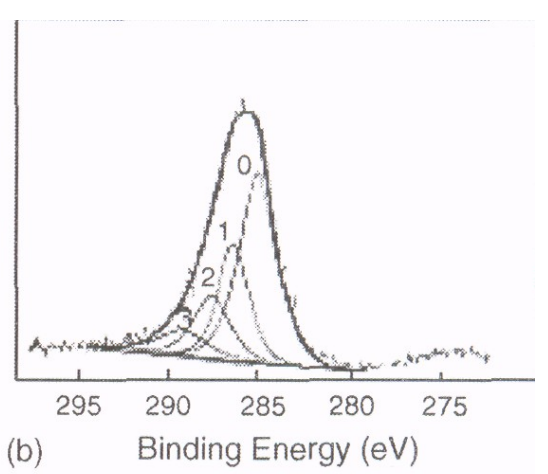

Fig. 1. XPS $C_{1 s}$ spectra of PBO fiber: (a) untreated PBO fiber and (b) $30 \mathrm{kGy}$ irradiated PBO fiber

The surface atom composition and the values of the binding energy (BE) of the untreated and the treated PBO fibers are given in Tables 2 and 3 , respectively. Noticeable changes are observed with the surface atom composition, polar oxygen percentage increases with the increasing irradiation dose (which is increased at intervals of $0-30 \mathrm{kGy}$ ). The oxygen content of the treated fibers is $22 \%$ higher than that of the untreated ПОЛЗУНОВСКИЙ АЛЬМАНАХ №1-2 2007 ones when the irradiation dose is $30 \mathrm{kGy}$. Moreover, a new polar atom (chlorine) $(0.66 \%$, $\mathrm{w} / \mathrm{w}$ ) appeared on the surface of the fibers when the irradiation dose is $30 \mathrm{kGy}$.

Table 2 - Surface atom composition of

\begin{tabular}{|c|c|c|c|c|}
\multicolumn{2}{|c|}{ PBO fiber } \\
\multirow{2}{*}{$\begin{array}{c}\text { Atom per- } \\
\text { centages (\%) }\end{array}$} & 0 & 10 & 30 & 40 \\
\cline { 2 - 5 } & & & & \\
\hline $\mathrm{C}$ & 75.78 & 74.97 & 73.59 & 74.96 \\
$\mathrm{O}$ & 15.84 & 18.35 & 19.37 & 18.50 \\
$\mathrm{~N}$ & 8.38 & 6.22 & 6.38 & 6.14 \\
$\mathrm{Cl}$ & 0 & 0.45 & 0.66 & 0.40 \\
\hline
\end{tabular}

Table 3 - The results of $C_{1 s}$ spectra fitting curve by XPS

\begin{tabular}{|c|c|c|c|c|c|}
\hline & Peak & $\begin{array}{l}\mathrm{BE} \\
(\mathrm{eV})\end{array}$ & Area & $\begin{array}{l}\mathrm{FWH} \\
\mathrm{M}\end{array}$ & $\begin{array}{l}\text { Correlat- } \\
\text { ive } \\
\text { structure }\end{array}$ \\
\hline $\begin{array}{l}\text { Un- } \\
\text { treated } \\
\text { PBO } \\
\text { fiber }\end{array}$ & $\begin{array}{l}0 \\
1 \\
2\end{array}$ & $\begin{array}{l}284.22 \\
285.33 \\
286.06\end{array}$ & $\begin{array}{l}9147.87 \\
5222.22 \\
3576.99\end{array}$ & $\begin{array}{l}2.18 \\
2.31 \\
3.92\end{array}$ & $\begin{array}{l}-\mathrm{C}-\mathrm{C}-\mathrm{C}- \\
-\mathrm{C}-\mathrm{O}- \\
-\mathrm{C}=\mathrm{N}-\end{array}$ \\
\hline $\begin{array}{l}30 \text { kGy } \\
\text { irradi- } \\
\text { ated } \\
\text { PBO } \\
\text { fiber }\end{array}$ & $\begin{array}{l}0 \\
1 \\
2 \\
3\end{array}$ & $\begin{array}{l}284.03 \\
285.09 \\
286.04 \\
287.30\end{array}$ & $\begin{array}{l}8446.21 \\
4266.56 \\
2841.27 \\
1626.44\end{array}$ & $\begin{array}{l}1.88 \\
1.54 \\
1.87 \\
2.65\end{array}$ & $\begin{array}{l}-\mathrm{C}-\mathrm{C}-\mathrm{C}- \\
-\mathrm{C}=\mathrm{N}- \\
-\mathrm{C}-\mathrm{Cl}- \\
-\mathrm{C}-\mathrm{O}- \\
-\mathrm{COOH}, \\
-\mathrm{C}-\mathrm{NH}_{2}\end{array}$ \\
\hline
\end{tabular}

However, as XPS indicated, the increasing oxygen content and chlorine content starts to decrease when the irradiation doses exceed 30 $k G y$. The reason may be that in the procedure of irradiation, the bond-break actions on the fiber surface increase proportionately with the increasing of the irradiation dose, at last, the bond-break actions produced by the excessive irradiation are more than the grafting actions on the fiber surface, i.e. the excessive irradiation energy breaks off the grafted polar groups again. As the result of XPS analysis indicated, the polar oxygen and chlorine contents decrease with the increasing of the irradiation dose when the irradiation dose is more than $30 \mathrm{kGy}$.

It is noted that the polar groups on the fiber surface can largely enhance the physical adsorption and the chemical reaction between the fiber and matrix. Therefore, the increasing of amount of oxygen, chlorine and nitrogen-containing polar groups on the PBO fiber surface plays an important role in improving the adhesion strength between the fiber and epoxy matrix.

Table 4 - The surface free energy of PBO fiber

\begin{tabular}{|l|l|l|l|}
\hline Surface energy $\left(\mathrm{mJ} \mathrm{m}^{-2}\right)$ & $\gamma_{\mathrm{f}}^{\mathrm{d}}$ & $\gamma_{\mathrm{f}}^{\mathrm{p}}$ & $\gamma_{\mathrm{f}}^{\top}$ \\
\hline & & & \\
Untreated PBO fiber & 9.9 & 9.4 & 19.3 \\
30kGy irradiated PBO fiber & 5.8 & 16.3 & 22.1 \\
\hline
\end{tabular}




\subsection{Fiber surface free energy}

The results determined by two liquid dynamic contact angle analysis (DCAA) of PBO fiber are showed in Table 4, it can be found that the total surface free energy and the polar component of the fiber increase with the increasing irradiation dose (which is increased at intervals of $0-30$ kGy), compared to the untreated fiber, the total surface free energy and the polar component of the fiber for $30 \mathrm{kGy}$ irradiation treatment are increased by $14.5 \%$ and $73.4 \%$, respectively. However, when the irradiation dose increases further more than $30 \mathrm{kGy}$, the total surface free energy and the polar component of the fiber decrease with the increasing irradiation dose. But there is not distinct change of the dispersive component of the irradiated fiber with the change of the irradiation doses.

The increasing of the total surface free energy and the polar component appear to be due to the increasing in the content of surface polar groups for the irradiated fiber. These polar groups $\left(\mathrm{COOH}, \mathrm{C}-\mathrm{C} 1, \mathrm{C}-\mathrm{NH}_{2}\right)$ decrease the contact angle of the fiber by the solutions. Therefore, the wettability of the PBO fiber is improved, too.

\subsection{Grafting reaction mechanism}

Fig. 2 shows the ${ }^{1} \mathrm{H}$ NMR spectrum of the model compound before and after irradiation, respectively. In the Fig. 2 (a), there are five different characteristic hydrogen elements in the structure of untreated PBO model compound, $\delta 8.50(1 \mathrm{H})$ and $\delta 8.33(1 \mathrm{H})$ [17] are the proton peaks of hydrogen 1 and hydrogen 2 in benzobisoxazole structure, respectively; $\delta 7.82(2 \mathrm{H})$ is the proton peak of hydrogen 5 in phenyl rings; $\delta 7.65(4 \mathrm{H})$ and $\delta 8.29(4 \mathrm{H})$ are the proton peaks of hydrogen 3 and the hydrogen 4 in phenyl rings. In the Fig. 2(b), the proton peaks of hydrogen $1-5$ are also exist, it indicates that the structures of the benzo ring in the benzobisoxazole structure and $\mathrm{p}$ phenyl rings are not changed by irradiation.

However, some new proton peaks appear compared with Fig. $2(a), \delta 3.11(6 \mathrm{H})$ is the proton peak of hydrogen 7 and hydrogen 9 in group $\mathrm{C}$ $\mathrm{NH}_{2}, \delta 4.30(4 \mathrm{H})$ and $\delta 4.80(2 \mathrm{H})$ are the proton peaks of hydrogen 6 , hydrogen 8 and hydrogen 10 in groups of $\mathrm{C} 1-\mathrm{CH}_{2}-\mathrm{C}$ and $\mathrm{HC}-\mathrm{OOH}$, at the same time, the proton peaks of hydrogen $1-5$ are shifted to low field affected by electronegative elements of $\mathrm{N}, \mathrm{O}$ and $\mathrm{Cl}$. The reason of this change is that some chemical reactions (breaking reactions, coupling reactions and grafting reactions) occur between PBO model compound and grafting agent in the procedure of $\gamma$-ray irradiation. First, a series of active radicals are produced due to the breaking reactions of the double bond $\mathrm{N}=\mathrm{C}$ in benzobisoxazole structure of $\mathrm{PBO}$ model compound and the epoxy ring of epichlorohydrin, then some active radicals couple again, some active groups, such as $\mathrm{C}-\mathrm{OOH}$ and $\mathrm{C}-$ $\mathrm{CH}_{2}-\mathrm{Cl}$, are introduced by grafting reactions on the model compound molecular structure, those polar elements $\mathrm{N}, \mathrm{O}$ and $\mathrm{Cl}$ change the chemical inert of PBO compound significantly.
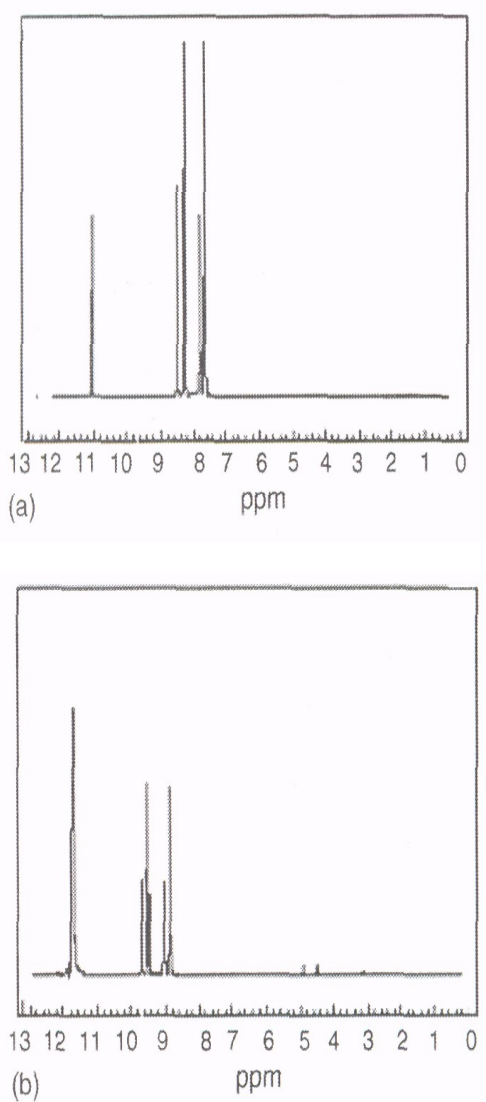

Fig.2. ${ }^{1} \mathrm{H}$ NMR spectra of PBO model compound: (a) untreated PBO model compound and (b) 30 kGy irradiated PBO model compound.

Proper controlling the irradiation condition can get optimum modification effect of PBO fiber surface. This result is corresponding to the result of XPS analysis. It can infer that the grafting reaction between PBO polymer and epichlorohydrin is as follows: 


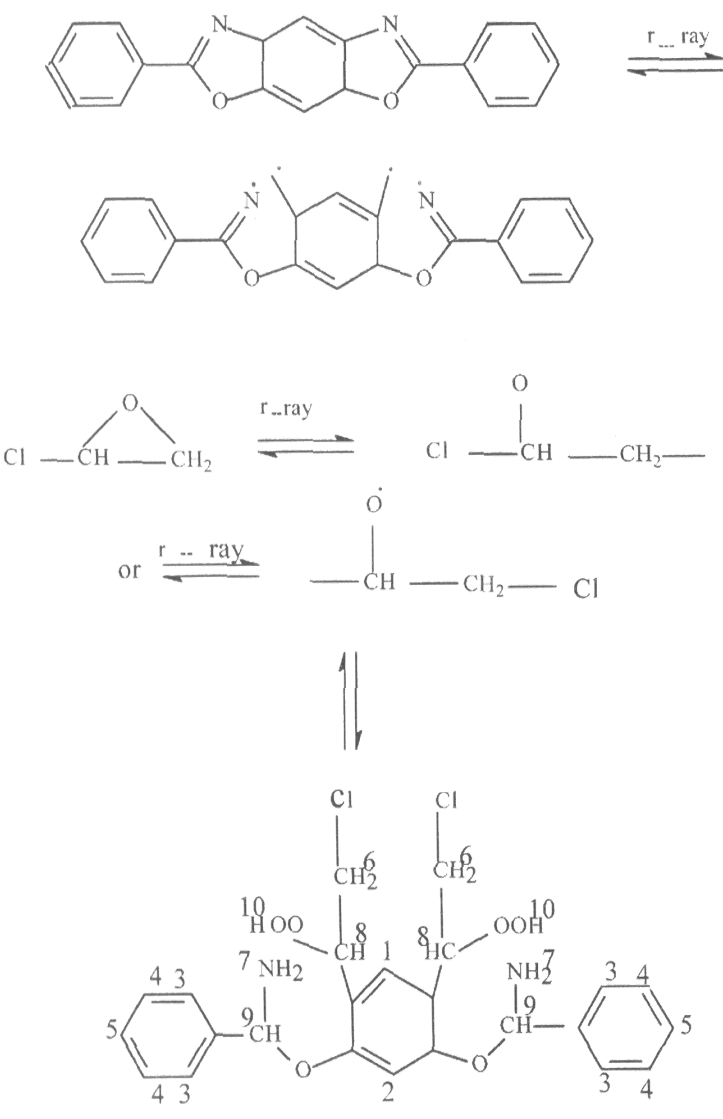

3.3. Surface topography

Fig. 3 shows the AFM images of untreated and 30 kGy irradiated PBO fibers, respectively. It can be found that the sizing changes of the surface topography are on a microscopic scale. Table 5 summarizes the results of roughness analysis of the irradiated and untreated fibers as obtained from the AFM images.

Table 5 - Surface roughness of PBO fiber

\begin{tabular}{|l|c|c|}
\hline & $\begin{array}{c}\text { Untreated PBO } \\
\text { fiber }\end{array}$ & $\begin{array}{c}30 \text { kGy irradi- } \\
\text { ated PBO fiber }\end{array}$ \\
\hline $\begin{array}{l}\text { Mean rough- } \\
\text { ness }(\mathrm{nm})\end{array}$ & 10 & 20 \\
$\begin{array}{l}\text { Maximum } \\
\text { height }(\mathrm{nm})\end{array}$ & 15 & 35 \\
Area $\left(\mu \mathrm{m}^{2}\right)$ & 4 & 4 \\
\hline
\end{tabular}

The results indicate that the mean surface roughness value is only $10-15 \mathrm{~nm}$ for untreated PBO fiber, but for $30 \mathrm{kGy}$ irradiated PBO fiber, it is become about $20-35 \mathrm{~nm}$, i.e. the $30 \mathrm{kGy}$ irradiated fiber surface becomes rougher with a mean surface roughness value twice that of untreated fiber. The interfacial adhesion between the irradiated PBO fiber and matrix may be enhanced by increasing the surface area (increasing roughness), which may provide more contact points and more mechanical interlocking between the fiber and matrix.

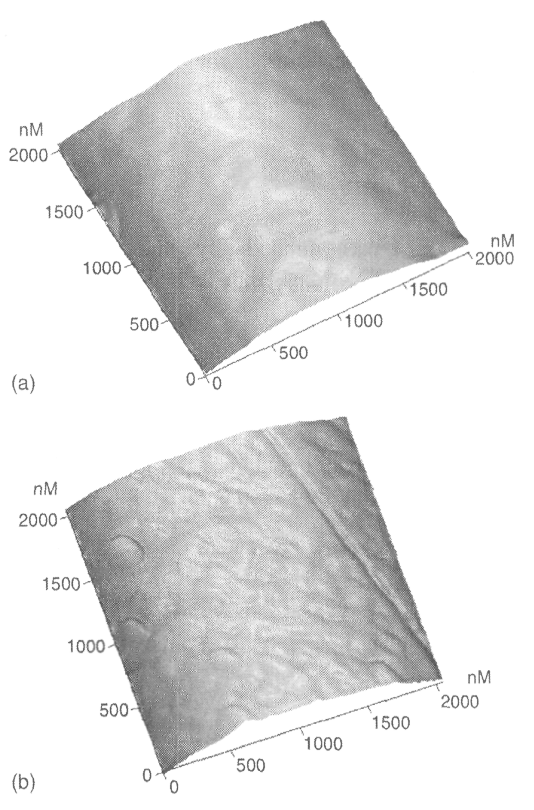

Fig.3. Surface morphology of PBO fiber by AFM: (a) untreated PBO fiber and (b) $30 \mathrm{kGy}$ irradiated PBO fiber.

\section{Conclusions}

(1) $\gamma$-ray irradiation can modified PBO fiber surface properties, some polar groups including oxygen, nitrogen and chlorine are produced by grafting reaction between epichlorohydrin and PBO polymer on the PBO fiber surface, at 30 kGy irradiation treatment, the oxygen content increases from $15.84 \%$ to $19.33 \%$ (by $22 \%$ ), chlorine content increase from $0 \%$ and $0.66 \%$ on the fiber surface, and the total surface free energy and the polar component of the fiber for $30 \mathrm{kGy}$ irradiation treatment are increased by $14.5 \%$ and $73.4 \%$, respectively.

(2) The irradiation grafting reaction mechanism is that the double bong $\mathrm{N}=\mathrm{C}$ in benzobisoxazole structure of PBO polymer and the epoxy ring of epichlorohydrin are opened by irradiation energy and produce active radicals, then some active radicals produced from epichlorohydrin react with the active radicals produced from $\mathrm{PBO}$ polymer at the breaking bond in PBO polymer.

(3) $\quad \gamma$-ray irradiation changes the surface morphology of PBO fiber, the fiber surface becomes from smoothness to roughness. The 30kGy irradiated fiber surface becomes rougher with a mean surface roughness value twice that of the untreated fiber.

\section{Acknowledgement}

This work was funded by the 863 Program 2002AA305109 of National High Technology Research and Development Plan.

\section{REFERENCES}


1.T. Kitagawa, K. Yabuki, J. Polym. Sci. Part B 38 (2000) 2937.

2.R.J. Davies. M.A. Montes-Moran, C. Riekel, RJ. Young, J. Mater. Sci. 36 (2001) 3079.

3.R.J. Day, K.D. Hewson, P.A. Lovell, Compos. Sci. Technol. 62 (2002) 153.

4.T.K. Lin, S.I. Wu, J.G. Lai, S.S. Shyu, Compos. Sci. Technol. 60 (2000) 1873.

5.Y.D. Huang, L. Liu, J.H. Qiu, L. Shao, Compos. Sci. Technol. 62

6.(2002) 2153.

7.S.-J. Park, M.-K. Seo, J.-R. Lee, J. Colloid Interface Sci. 268 (2003) 127.

8.J.-M. Park, D.-S. Kim, S.-R. Kim, Colloid Interface Sci. 64 (2003) 431.

9.[8] R.J. Young, R.J. Day, M. Zakikhani, J. Mater. Sci. 25 (1990) 127.
10.S. Yalvac, JJ. Jakubowski, Y.H. So, A. Sen. Polym. 37 (1996) 4657.

11.R.H. Li, Y.D. Huang, J.H. Qiu, Compos. Sci. Technol. 63 (2002) 179. [11] H.F. Ha, J.L. Wu, Macro-molecule Irradiation Chemistry, Beijing

12.University Press, Beijing, 2002.

13.S. Chwastcak, J. Interface Sci. 42 (1973) 298.

14.Y.D. Huang, J.H. Qiu, L.X. Liu, J. Mater. Sci. 38 (2003) 759.

15.Y.-L. Hsieh, M. Wu, D. Andres, J. Colloid Interface Sci. 144 (1991) 127.

16.Y.Z. Wang, Handbook of Chemistry, Beijing University Press, Beijing, 1997.

17.M.J. Reis, A.M. Botelho Do Rego, J.D. Lopes Da Silva, J. Mater. Sci. 30 (1995) 118.

18.D.H. Williams, L. Fleming, Spectroscopic Methods in Organic Chemistry, McGraw-Hill Publishing Company, England, 1995, p. 83. 